\title{
Die Parteiautonomie im chinesischen internationalen Privatrecht
}

Das Recht der Volksrepublik China im Lichte eines Vergleichs mit deutschem und europäischem Kollisionsrecht

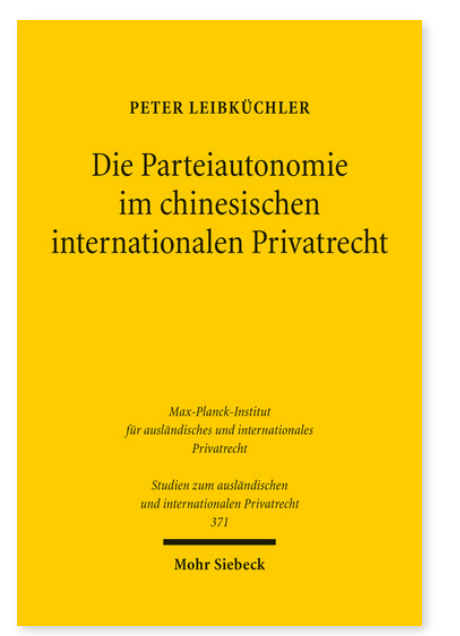

2017. XXIV, 292 Seiten. StudIPR 371

ISBN 978-3-16-154968-7

DOI 10.1628/978-3-16-154968-7

eBook PDF 74,00€

ISBN 978-3-16-154967-0

fadengeheftete Broschur 74,00€
Für jede international-privatrechtliche Streitigkeit stellt sich die wichtige Frage des anwendbaren Rechts. Die angemessene Antwort suchen nationale Kodifikationen heute in zunehmendem Maße in der Delegation der Bestimmung des anwendbaren Rechts auf die Parteien selbst. Die bei der Einräumung dieser Freiheit zu beachtenden Umstände stehen im Spannungsfeld von Parteiwille, staatlicher Souveränität und Rechtssicherheit. Die VR China hat im Jahre 2010 ein neues Gesetz zum internationalen Privatrecht verabschiedet und hierin erstmals der Parteiautonomie einen prominenten Platz eingeräumt. Peter Leibküchler bietet eine Analyse dieser neuesten rechtlichen Entwicklung in Gesetzesrecht, Literatur und staatlicher Rechtsprechung. Ein besonderes Augenmerk legt er dabei auf die gerichtliche Umsetzung und die Frage der tatsächlichen Ermittlung und Anwendung ausländischen Rechts. Die Untersuchung erfolgt als Vergleich mit den entsprechenden deutschen bzw. europäischen Regelungen.

Peter Leibküchler Geboren 1982; Studium der Rechtswissenschaften mit wirtschaftswissenschaftlicher Zusatzausbildung an der Universität Bayreuth; Masterstudium an der China-EU School of Law in Peking; Masterstudium Europäische Moderne Geschichte und Literatur an der Fernuniversität Hagen; Wissenschaftlicher Mitarbeiter am Max-Planck Institut für ausländisches und internationales Privatrecht in Hamburg; Forschungsaufenthalt an der China University for Political Science and Law in Peking; Referendariat in Hamburg; seit 2016 stellvertretender deutscher Direktor am Deutsch-Chinesischen Institut für Rechtswissenschaft in Nanjing.

Jetzt bestellen:

https://mohrsiebeck.com/buch/die-parteiautonomie-im-chinesischen-internationalen-privatrecht-9783161549687? no_cache $=1$

order@mohrsiebeck.com

Telefon: $+49(0) 7071-923-17$

Telefax: $+49(0) 7071-51104$ 